\title{
InnoPulse: a Tool to Support Collaborative Reflection in Creativity-Driven Engineering Projects
}

\author{
Danielly de Paula \\ Hasso Plattner Institute \\ University of Potsdam \\ danielly.depaula@hpi.de
}

\author{
David Hahn \\ Hasso Plattner Institute \\ University of Potsdam \\ david.hahn@hpi.de
}

\author{
Christoph Matthies \\ Hasso Plattner Institute \\ University of Potsdam \\ christoph.matthies@hpi.de
}

\author{
Falk Uebernickel \\ Hasso Plattner Institute \\ University of Potsdam \\ falk.uebernickel@hpi.de
}

\begin{abstract}
To equip students with the practical capability to innovate, academic institutions are promoting industry collaboration projects, where students use creative approaches, such as, design thinking (DT), to solve complex business challenges. In creative team work, the ability to reflect upon and improve team dynamics is vital. However, research on the role of digital technology to support collaborative reflection is still in its infancy. This study presents a digital solution that uses micro surveys as an additional source of information for Educational Data Mining (EDM) analyses to support the collaborative reflection of students working in creativity-driven engineering projects. Using design science research, we identify the design requirements of the InnoPulse tool, implement the corresponding design features and evaluate our digital solution in a real-world educational setting. Our findings pave the way for the potential of ad-hoc data collection strategies to improve the collaborative reflection of students applying DT methods.
\end{abstract}

\section{Introduction}

Due to the competitive environment of today's business world, scholars argue about the importance of embedding innovative thinking throughout the university curriculum [1]. Accordingly, business and engineering schools, such as the University of St. Gallen and Karlsruhe Institute of Technology, are expanding their efforts to teach students how to innovate through project-based classes in collaboration with the industry [2]. University-industry collaborations aim to benefit both sides, whereby industry gains valuable new knowledge of technologies and higher education institutions (HEIs) enabling students to develop their skills by working on real-world problems [3]. Business challenges, however, are often wicked, ambiguous, and uncertain, which makes them hard to solve. To assist students in solving business challenges proposed by industry partners in their class projects, scholars and educators usually advocate the embedding of design thinking (DT) in the students' learning process $[1,3]$.

Design thinking is a well-established user-centered approach to innovation that is valued in the business world for supporting the development of desirable, novel products [4]. Therefore, the importance of encouraging students to use design thinking in projects within the context of university-industry collaboration is becoming increasingly recognized [2]. For instance, it has been found that using design thinking to develop digital solutions leads to improved needfinding and the ability to offer individualized products [5]. Moreover, scholars found that teaching design thinking to students offers them higher levels of motivation and empowerment [6], and a competitive advantage when seeking jobs [7].

According to scholars, reflective practice forms a crucial plank of design thinking especially when it is used to solve wicked business challenges [8]. As a pedagogical tool, reflective practice involves the ability to consider one's own experiences both during and after applying knowledge to practice [9]. Reflection is particularly important to creative work, where assumptions need to be tested with users and solutions iteratively reframed based on user feedback [10]. When conducted in a group, reflection helps students discuss their experiences, encourage critical thinking about team experience and solidify lessons learned [11]. According to Hey et al. [8], the ability to define action plans based upon reflection is the hallmark of effective teams.

While there are many studies that investigate reflective practice in educational contexts, research on the role of digital technology to support collaborative reflection in creativity-driven engineering projects lies still in its infancy [10]. In the particular context of students using design thinking, Schoormann et al. [10] are the first to propose a prototype of a software solution that enables students to reflect upon the entire process of a design thinking project and its outcomes. In our study, 
we aim to extend the work of Schoormann et al. [10] by using concepts from Educational Data Mining (EDM) to develop a digital solution that uses micro surveys to gauge changes in team dynamics. The purpose of the tool is to support student teams during collaborative reflections in the context of applying design thinking to creativity-driven engineering projects. The following research question (RQ) guides this study:

RQ: How can we design a digital solution that uses micro surveys to support the collaborative reflection of students working on creativity-driven engineering projects?

From a methodological point of view, we used Design Science Research (DSR) to develop and evaluate InnoPulse, a digital solution that supports the collaborative reflection of students working in creativity-driven engineering projects. This study contributes to the literature on data-driven teaching improvement and teamwork analysis by proposing a mobile solution to assist the reflective practice of students using design thinking for engineering projects in the context of university-industry collaboration.

\section{Research Background}

\subsection{Collaborative reflection support for design thinking in education}

Design thinking is gaining increasing traction in engineering education research due to the belief that a shift from a technology-oriented perspective to a user-oriented perspective is essential for students seeking to work in engineering [2]. As a problem-solving approach, design thinking is often used to solve wicked real-world problems in ambiguous settings [12]. A range of models to learn DT have been proposed by professional educators, such as the Hasso Platter Institute D-School model [13], and academics, such as the design thinking micro cycle $[14,2]$. Although the models differ in some steps, the learning foundation of all of them follow the dichotomy between diverging and converging [1]. While diverging enables teams to explore the problem space creatively and to experiment with diverse ideas, converging forces teams to learn how to make decisions in ambiguous situations. When diverging and converging, students have to question and analyze possible directions and the potential impact of their decisions on the journey to the solution. To do that, it is recommended that students engage in reflective practices $[1,10,11]$.

Reflection is particularly important when addressing complex business challenges [10]. In the context of creative work, it is recommended that teams adopt a conscious reflection position about their own experience (e.g., in the form of previous prototypes and solutions), and seek to frame and re-frame the situation based on the lessons learned [9]. A particular scenario is when teams need to conduct several iterations of prototyping and iteratively reflect on their learning in order to continuously improve their solutions [2]. Design thinking teams leverage a variety of representations to reflect on activities, such as reflection-in-action (i.e., where assumptions and alternatives are evaluated during the action) and reflection-on-action (i.e., the retrospective analysis of actions and their effects) [9, $10]$.

Although the importance of engaging in reflection has been discussed in the literature [1, 15], little is known about how digital solutions can support teams to perform collaborative reflection in the context of design thinking [10]. While most tools for reflection focus on supporting individual reflection, thereby neglecting the benefits of group reflection [15], one attempt to develop a digital solution for collaborative reflection for student teams using design thinking is described in Schoormann et al. [10]. The authors propose a complex software tool able to be used overy the course of an entire design thinking project [10] and involving extensive user interaction through a computer, such as through discussion forums, wiki and messaging systems. When considering the recommended setup for spaces aimed at fostering creativity [16], a barrier for users is their affordability of computers. Because of this, ensuring high user participation in creative teams can be challenging. This barrier is also highlighted by Schoormann et al. [10] and the authors call for further research on "how to best [...] involve each team member in the reflection processes without being hindered by operating a tool" [10]. To lower any such barriers to user interaction, scholars recommend applications that use micro surveys, as long as their sole purpose is to measure changes in the dynamics of creative teams [17]. Through digital micro surveys, users are occasionally given the option to answer single questions on their smartphones to measure the team's dynamics, without causing any disruption to their work [17].

Based on the presented literature, we extend the work of Schoormann et al. [10] by developing a digital solution that supports student teams to perform reflection sessions, while requiring less user interaction when measuring changes in team dynamics. We employ micro surveys available through the InnoPulse system to measure team dynamics and use concepts from the fields of data mining and data visualization to allow the analysis of the data for guided reflection sessions. 


\subsection{Educational Data Mining}

Previous research that sought to address the lack of detailed, high-resolution data on learners has relied upon data collected form additional sources, such as social network data [18] or even lecturer's notes [19]. Traditional student assessment methods (e.g., exams) were previously considered the main tools for investigating students' learning progress. However, exams can only provide information on specific traits at specific points in time, in addition to being time-consuming and stressful. With the continuing rise of digitization and the pervasive usage of digital technologies in education and learning, more sophisticated techniques and available data sources can be used to gain insights into learners' progress and issues.

These approaches have been summarized under the title of Educational Data Mining (EDM). The International Educational Data Mining Society defines their discipline as "exploring the unique [...] data that come from educational settings [...] to better understand students, and the settings which they learn in" [20]. Data on learners are generated in a variety of digital systems that students interact with on a daily basis [21], such as different learning management systems [22]. In these scenarios, web mining approaches can be applied to student data in log files and databases [23]. In Massive Open Online Courses (MOOCs), where student collaboration is digital by default, the interactions with the platform are analyzed and studied [24]. If designed well, such measurements can provide insights into how students behave, communicate, and participate in learning activities. EDM studies mainly cover three core application areas [25]:

- Improving the academic development of students which include learning strategies, improvement of students' skills and monitoring of their motivation.

- Predicting student's performance to enable educators to intervene and provide assistance. Examples include predicting and providing support to students at risk of attrition [26, 27].

- Improving educational plans and curricula, and different types of feedback in online teaching models.

Within the EDM application area of improving the academic development of students, one of the main questions is how to construct systems that can identify learning behaviors [28, 29]. This is achieved by analyzing and extracting data contained in educational databases. By employing data visualization approaches on a subset of the learner data, acquired through data mining, student behaviors can be revealed and better understood [29].

Accordingly, this study adopts EDM approaches and the analysis of additional learner data sources to propose a digital solution aimed at supporting students in collaborative reflection in creativity-driven engineering projects using design thinking. An improved understanding of students' learning behaviors when using design thinking for engineering projects can form the basis for developing user modelling mechanisms to predict learner behavior and customize learner support.

\section{Methodology}

This study draws on the Design Science Research paradigm to develop and evaluate a digital artifact that supports collaborative reflection of students working in creativity-driven projects. The DSR paradigm allows to create knowledge through building and evaluating information technology artifacts [30]. It is widely adopted in Information Systems (IS) research due to its potential to draw from existing theories to rigorously develop a solution with relevant impact on practice [30]. For this study, we followed the iterative design science research methodology (DSRM) [30]: 1) problem identification and motivation; 2) definition of objectives for a solution; 3) design and development of the approach; 4) demonstration, 5) evaluation, and 6) communication. In our study, the six steps of the DSRM were categorized into three phases that are described in the following sections.

\subsection{Initial Design}

To understand how to better support students to perform collaborative reflection sessions, we interviewed ten professionals who had between three and seven years' experience of guiding novice practitioners on how to perform reflection sessions in the context of design thinking projects. In particular, our interview guide focused on collecting data related to the kind of actions that teams tend to perform in order to continuously reflect on their behaviors and process outcomes. The interviewee sample (see overview in table 1) included coaching practitioners who were part of a professional educational program and the teaching team of students doing a master's course.

The results showed that, although creative teams recognize the importance of performing collaborative reflection, they lack a tool that can be used 
Table 1: Overview of practitioners in sample.

\begin{tabular}{cccccl}
\hline Interview & Code & Experience & Age & Gender & Area of work \\
\hline $\mathbf{1}$ & $\mathrm{c} 1$ & 7 years & 40 & $\mathrm{f}$ & $\begin{array}{l}\text { Professional } \\
\text { Education }\end{array}$ \\
\hline $\mathbf{2}$ & $\mathrm{c} 2$ & 5 years & 30 & $\mathrm{~m}$ & $\begin{array}{l}\text { Research \& } \\
\text { Development }\end{array}$ \\
\hline $\mathbf{3}$ & $\mathrm{c} 3$ & 3 years & 32 & $\mathrm{f}$ & $\begin{array}{l}\text { Student } \\
\text { Education }\end{array}$ \\
\hline $\mathbf{4}$ & $\mathrm{c} 4$ & 5 years & 35 & $\mathrm{~m}$ & $\begin{array}{l}\text { Innovation } \\
\text { Research }\end{array}$ \\
\hline $\mathbf{5}$ & $\mathrm{c5}$ & 3 years & 29 & $\mathrm{~m}$ & $\begin{array}{l}\text { Professional } \\
\text { Education }\end{array}$ \\
\hline $\mathbf{6}$ & $\mathrm{c6}$ & 3 years & 31 & $\mathrm{f}$ & $\begin{array}{l}\text { Professional } \\
\text { Education }\end{array}$ \\
\hline $\mathbf{7}$ & $\mathrm{c7}$ & 2 years & 25 & $\mathrm{~m}$ & $\begin{array}{l}\text { Student } \\
\text { Education }\end{array}$ \\
\hline $\mathbf{8}$ & $\mathrm{c} 8$ & 3 years & 27 & $\mathrm{~m}$ & $\begin{array}{l}\text { Student } \\
\text { Education }\end{array}$ \\
\hline $\mathbf{9}$ & $\mathrm{c9}$ & 3 years & 28 & $\mathrm{f}$ & Consulting \\
\hline $\mathbf{1 0}$ & $\mathrm{c10}$ & 3 years & 28 & $\mathrm{~m}$ & Consulting \\
\hline
\end{tabular}

to systematically support (and record) their team reflections. As a consequence, teams tend to forget how their perception and behaviors have changed throughout the phases of a project, which, in turn, does not support future reflection sessions.

To develop a solution to the identified problem, it was necessary to first identify design requirements. To this end, we conducted interviews with student teams participating in the SUGAR network ${ }^{1}$, a global network that brings together students, universities and companies for the future of innovation through a new learning experience. Normally, master students from universities partner with a large organization to work for nine months on a design challenge proposed by a company. The syllabus of the master course is based on design thinking (for a description, see Uebernickel et al. [14] and Wiesche et al. [2]). Each team is guided by the teaching team from each university. In total, 12 master's students were selected, working in four different projects with firms operating in the fields of manufacturing, electronics and pharmaceuticals (see Table 2). The students were registered on different master's programs such as Digital Health, IT-Systems Engineering, and Cyber Security. The sample size is in line with previous work that focused on developing design requirements for digital solutions [10]. Based on an analysis of the previously proposed solutions in the related literature and insights from the 22 conducted interviews, we derived design requirements for the

\footnotetext{
${ }^{1}$ https://sugar-network.org/
}

InnoPulse system. These are summarized in Table 3.

Table 2: Overview of student sample.

\begin{tabular}{clll}
\hline Team no. & Project Area & Code & Field of Study \\
\hline \multirow{3}{*}{1} & \multirow{2}{*}{ Waste Water } & g1 & Digital Health \\
& & g2 & Digital Health \\
& & g3 & IT-Systems Engineering \\
\hline \multirow{2}{*}{2} & \multirow{3}{*}{ Car Manufacturing } & b1 & IT-Systems Engineering \\
& & b3 & Digital Health \\
& & t1 & Cyber Security \\
\hline \multirow{3}{*}{3} & \multirow{3}{*}{ Pharmaceuticals } & t2 & Digital Health \\
& & t3 & Digital Health \\
& & r1 & IT-Systems Engineering \\
\multirow{2}{*}{4} & \multirow{2}{*}{ Media } & r2 & IT-Systems Engineering \\
& & r3 & Cyber Security \\
\hline
\end{tabular}

Students were registered on different master's programs such as Digital Health, IT-Systems Engineering, and Cyber Security. The sample size is in line with previous work that focused on developing design requirements for digital

\subsection{Development}

Based on these design requirements, InnoPulse was implemented as an Android smartphone app with an administration backend used in a web browser. Ideally, participants should be able to answer survey questions with as little disruption as possible and, to that end, we displayed the survey on a device that team members interect with regularly during their work activities. For design thinking teams, this device often involves a smartphone, which is used to check times, set timers and communicate with others, rather than (dedicated) hardware or a separate desk-top computer or laptop. Smartphone operating systems also feature notification systems that can be customized by team members (e.g., muted), based on the tasks being performed, which InnoPulse can make use of. Due to the personal nature of smartphones, survey answers can be attributed to individual team members. Considering that setting up surveys for multiple teams with associated display times and viewing survey results and graphs require a larger display and more efficient inputs than are available on a smartphone, we also implemented a web application. Therefore, the backend was implemented as a web app that can be used on any device with a web browser. Figure 1 illustrates the system architecture specifics.

The InnoPulse backend web application can be used by coaches and educators to define questions to 


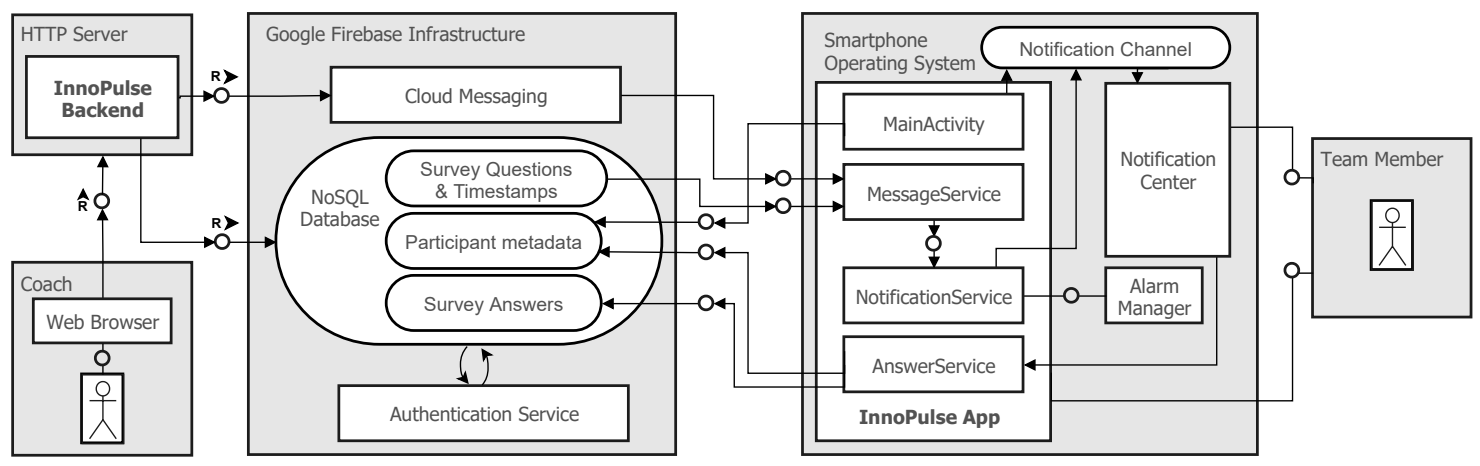

Figure 1: Overview of the InnoPulse system architecture employing a smartphone app and the InnoPulse backend, modeled in Fundamental Modeling Concepts notation [31]

be posed to participating team members in the form of push notifications. A targeted time for when the question should be displayed to participants can be set. Furthermore, the backend contains a dashboard displaying the answers to the questions.

The InnoPulse Android App implements the underlying logic used to retrieve, display and answer the micro-survey questions. However, users do not need to open the app to answer questions, which are handled by the native notification center of the smartphone operating system and appear just as any other notification, e.g., for a new chat message. The application itself is mainly used to initially register participants with their name and a unique team ID that is given them. This information, together with the phone's device token, is stored in a central database and is later used to send out questions. The user data (first name and device token), questions, answers, and timestamps, are stored in a Google Firebase Real-Time Database ${ }^{2}$, a database which allows storing arbitrary data in JSON format. The database allows a simple form of access control through node-based rule sets. This allows data to be stored on a team-by-team basis with rules allowing access to nodes only to those affiliated with a specific team. Authentication solutions are provided by the Firebase Authentication ${ }^{3}$ tools.

The app consists of three main services: the MessageService, the NotificationService, and the AnswerService. The MessageService is responsible for receiving messages from the server that contain survey questions for team members. Every message includes the question itself and the time at which the app should display the related notification. The NotificationService is responsible for creating a notification and displaying it to the user. The AnswerService is opens when the user

\footnotetext{
${ }^{2}$ https: //firebase.google.com/products / realtime-database

${ }^{3}$ https: //firebase.google.com/docs/auth
}

presses one of the actions provided in the notification center. The intent contains the label of the pressed answer as well as the team ID and the question ID. The AnswerService then connects to the database and enters the provided answer together with a current timestamp and the team member's name. The notification then disappears from the notification center.

\subsection{Demonstration, evaluation and communication}

User acceptance of a technology is influenced by the user's perception of its usefulness and its ease of use [32]. Perceived usefulness refers to the extent to which users believe the technology helps them with carrying out a specific task, while the perceived ease of use is "the degree to which a person believes that using a particular system would be free of effort"[32]. These two components affect user attitudes towards a technology and directly influence their propensity to utilize a particular technology.

Considering that InnoPulse is a prototype, we assessed its usefulness and ease of use through the applicability of the prototype in the context of real projects. In this way, we asked the same sample of students that were interviewed to install the InnoPulse app on their smartphones to use the app for five days while they were working on their projects. Questions included: "what is the team mood now?" and "what is the current situation?". Questions were scheduled to be sent every two hours and the answers were provided on a 5 point Likert scale illustrated as emojis (as shown in Figure 2). At the end of each day, teams were given access to the dashboard to collectively visualize their answers and reflect on them. We observed the reflection sessions in order to investigate whether the app was addressing the needs of the teams. After the five days, we conducted another round of interviews 
with the teams to delve deeper into the insights we had already observed and to collect more in-depth data on the collective experience of the teams. Additionally, we interviewed the same professional coaches to get their views on the further applicability of InnoPulse. The insights derived from the evaluation phase are explained in section 4.3.

Finally, the last step of the DSRM is to communicate the results to a wider audience through a research publication to diffuse the resulting knowledge. With this paper we aim to provide a comprehensive first step in achieving that goal.

\section{Results}

In this section we explain the design requirements derived from the literature review and from the interviews. We then describe the features that were implemented based upon the design requirements. Third, as recommended by the DSR approach, we analyze the results of our evaluation procedures.

\subsection{Design Requirements}

To provide a theoretical foundation and practical relevance, the design requirements were derived from the literature and from interviews with professionals and students. The needs of our interviewees were translated into common and specific requirements. An illustration of the requirements and their particular code is displayed in Table 3.

The early stages of SUGAR projects tend to have high a level of uncertainty and ambiguity regarding roles and expectations. During the first months of the projects, the teaching team needs to encourage the teams to conduct reflection sessions to discuss their perceptions of the team performance in order to help teams develop their tolerance for ambiguity and uncertainty. At the same time, the teaching team empowers the students to take ownership of the project and act independently with self-determination. In this way, while the teaching team is initially involved in identifying and analyzing behaviors during the reflection sessions, after some time, the students develop their ability and confidence to do it by themselves. Accordingly, a common requirement for both the coaches (or teaching team) and students is to be able to send questions to the teams (CRq1).

In the context of creative work, there are many tools that can aid a team's work. As interviewee B3 pointed out, "There are so many tools already. But as most of them bring little benefit, they are usually quickly discarded". Therefore, answering the questions must be optional (SRq2) and answering them should be easy (SRq1).
Additionally, creative teams need time and space to allow creativity to flourish. Their work should not be unnecessarily disrupted. As interviewee C8 mentioned, "The worst thing you can do is to disrupt the work of the team by asking them questions. They were probably doing fine, at least until you stopped their productivity". It is important, therefore, that the app does not disrupt a teams' workflow (SRq3).

To enable collaborative reflection, it is essential that teams are able to visualize the data collected from them so they can analyze it $[10,28]$. The objective of the analysis and visualization of data is to enable students to identify patterns in the data in order to support decision making. Having access to the visualization of the descriptive analysis of the data (e.g., summaries about learner's behavior) is less time-consuming and easier to interpret than inspecting log data. Additionally, considering that creative teams require a continuous framing and (re) framing of their specific situations, it is important to provide them with graphic visualizations of their progress [10]. Graphic visualizations enable teams to visualize and reflect on how their experience has changed over time depending on particular situations, which in turn, helps them to develop more informed action plans. It also makes it possible for coaches and students to investigate how students develop their learning behavior [23]. Accordingly, a common requirement for both coaches and students is to have access to the visualization of the analysis of their answers (CRq2).

\subsection{Design features}

The InnoPulse system aims to enable teams to perform collaborative reflection by using micro surveys to collect data points from team members over a period of time. The features of InnoPulse were developed based upon the design requirements identified by interviewees involved in DT projects. Table 3 illustrates these features and the corresponding design requirements.

The question sender, i.e., a team coach, can use the user dashboard (DF1) of the web application to send questions to the team (CRql). Attributes of the question include the team ID, which ensures that only users with the same team ID receive the question on their smartphone notification center. To send the question, a connection to a hosted cloud service with high availability is established, before the service distributes the question to all registered devices under the selected team ID. The question is also stored in a database and a timeDiff attribute defines the time that a question is answerable before it becomes irrelevant.

Team members receive push notifications at the 
times set for individual questions on their mobile phones and have the possibility of answering them directly in the notification center (DF3). It is not necessary to open the app and therefore answering the question is easy (Srq1). Figure 2 illustrates how teams can answer the questions using the notification center. The example question shown in the figure is "how is the team mood right now?". This type of mood collection for teams is common practice within software teams [33]. The notification alert is deactivated by default (DF5) so it does not disrupt the workflow of the team (SRq3).

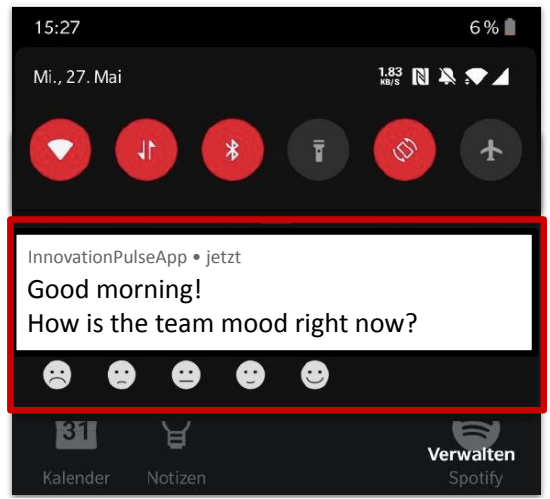

Figure 2: An InnoPulse survey notification (highlighted in red) in the Android notification center with inline answering options.

Questions are not mandatory (SRq2) and in case the user does not answer them, they can dismiss the notification and, failing that, the notification is automatically dismissed after a certain time defined by the question sender (DF4). The questions are pre-defined by the question sender. Three different types of questions can be asked:

- Type 1: A simple piece of information that can be acknowledged by the recipient.

- Type 2: A question with three given answer options.

- Type 3: A question that can be answered on a 4 or 5-point Likert scale.

When answered, the questions are analyzed and displayed in a graphic visualization (CRq2). To display the answers, graphic visualizations as data representations were implemented (DF2). To enable the user to understand different learning behaviors, the data representation shows how answers from each individual team member change over the time. Figure 3 illustrates an example of how the mood data of a team are graphically represented. Each user is represented by a different color. The names were omitted due to privacy reasons. The $\mathrm{x}$-axis shows the time of the collected data points and the $y$-axis shows the answers in a Likert scale format.

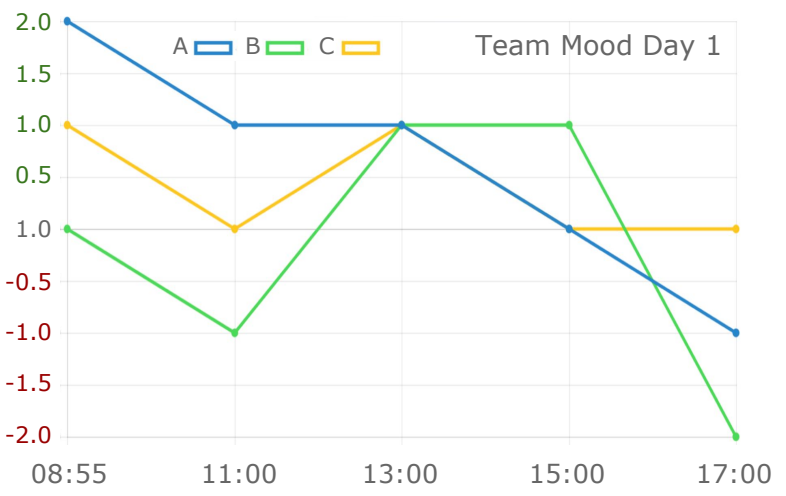

Figure 3: Line graph of the mood development in a design thinking team (higher is better) over a full working day, with mood data collected by InnoPulse.

\subsection{Demonstration and evaluation}

First, we demonstrated the applicability of InnoPulse in a real-world situation. Accordingly, we asked the same master's students to install InnoPulse on their phones and to use it for a period of five working days. At the end of each day, we observed the team while they were conducting reflections sessions and after the five days they were interviewed. Since InnoPulse was still a prototype, we mainly focused on qualitatively investigating its usefulness and ease of use [32]. During the interviews, the participants mentioned that the graphic visualizations were helpful to understand what happened at specific points in time. Interviewees mentioned that they tend to forget situations that happened in the morning and InnoPulse helped the teams to remember and reflect on the experiences which then made it possible for the teams to identify patterns and understand their differences in their perception of specific situations. However, we also learned that the answer timeframe is crucial. As mentioned before, teams can answer questions during a timeframe that is predefined by the question sender (the "answer window"). As part of the evaluation, we found that it is challenging and sometimes uncomfortable for the students to compare their answers, considering that it might happen that they do not answer the question at the same time. As interviewee R1 mentioned: "Yeah, this makes me look like the grumpy team member. The truth is: Everyone was mad at this point, but everyone answered previously, while I still had to give 
Table 3: Overview of design requirements and design features of the InnoPulse system.

\begin{tabular}{|c|c|c|c|}
\hline $\begin{array}{l}\text { Design } \\
\text { Requirements }\end{array}$ & $\begin{array}{l}\text { Coach } \\
\text { (teaching team) }\end{array}$ & Students & Design features \\
\hline \multirow{2}{*}{$\begin{array}{l}\text { Common } \\
\text { requirements }\end{array}$} & \multicolumn{2}{|c|}{ Send questions to the team (CRq1) } & User dashboard (DF1) \\
\hline & $\begin{array}{l}\text { Access to the vis } \\
\text { of the answers ( } C\end{array}$ & of of the analysis & Data representation (DF2) \\
\hline \multirow[t]{3}{*}{$\begin{array}{l}\text { Specific } \\
\text { Requirements }\end{array}$} & & $\begin{array}{l}\text { Answering the questions } \\
\text { must be easy (SRq1) }\end{array}$ & $\begin{array}{l}\text { Question can be answered } \\
\text { in the notification center } \\
\text { without the need to launch } \\
\text { the app (DF3) }\end{array}$ \\
\hline & & $\begin{array}{l}\text { Answering questions } \\
\text { must be optional (SRq2) }\end{array}$ & $\begin{array}{l}\text { Notification is dismissed } \\
\text { either by the user or after a } \\
\text { certain period of time } \\
\text { (pre-defined) (DF4) }\end{array}$ \\
\hline & & $\begin{array}{l}\text { It does not disrupt the } \\
\text { workflow of the team } \\
\text { (SRq3) }\end{array}$ & $\begin{array}{l}\text { Notification alert is } \\
\text { deactivated by default } \\
\text { (DF5) }\end{array}$ \\
\hline
\end{tabular}

my answer." In this way, questions that ask for a current feeling might yield different answers based upon difference in time between any two responses.

Second, we analyzed our perception of the reflection sessions that we observed. This showed that InnoPulse improved the communication of the teams by offering them a shared team history with a narrative that was unique to them. Having a shared team history enabled the students to better engage in conversations about the team dynamic. Without a team history, students claimed to usually forget about what happened during the day, neglecting, discussion points that were relevant at the time. Moreover, we noticed that some students were more interested in engaging in collaborative reflections than others. The students who were interested in group reflections were more susceptible to changing their behaviors the next day and improve the dynamics within the team.

Third, for further practical relevance, we interviewed the same professional coaches to understand what value InnoPulse could bring to them. Interviewees mentioned that InnoPulse could support them in collecting real time information from the team to identify when it is necessary for them to intervene. For instance, in many cases one coach needs to give attention to several teams and InnoPulse could help the coach to identify which team need attention the most. As interviewee C5 mentioned, "What this would be perfect for is following this up with my input. Did everyone understand what I said? Can they act on the new instructions, or are they stuck? Something I need to know, but I don't want to interrupt them again”.

\section{Discussion}

The purpose of embedding design thinking into the curriculum of universities is to create an environment that encourages students to build creative confidence [34] and to enable them to experience a research methodology that is increasingly practiced within industry [35]. When working with design thinking to solve complex business challenges, teams need to make decisions along the way and a key fundamental practice to make informed decisions is the ability to perform collaborative reflection. To aid teams perform collaborative reflection, we developed InnoPulse.

InnoPulse is a digital solution that uses micro surveys to prompt teams to answer single questions that are relevant to analyzing the dynamics that influence their learning behavior. The intention of developing InnoPulse is to support academic institutions that are 
making the effort to encourage students to develop their innovative mindset by working on real-world problems in cooperation with industry. Examples of universities promoting university-industry cooperation can be found in Wiesche et al. [2]. Additionally, InnoPulse attempts to reduce the complexity of using technology to aid reflection sessions by identifying design requirements and implementing design features that are solely focused on measuring and analyzing changes in team dynamics. By doing that, we extend the work of Schoormann et al. [10] by addressing a limitation in their study. Due to the possibility of having access to the analyzed data representations at any given moment, our digital solution supports reflection-in-action and reflection-on-action which are well known representations of reflective practices as explained by Schön [9]. In this way, it is possible to reflect on experiences as they occur, or to reflect on them retrospectively.

By using EDM approaches to continuously analyze the given answers, InnoPulse enables teams to observe their development and comprehend how their team members perceive their experiences. Moreover, capturing data within the system allows the teaching team to analyze the temporal order of individual experiences of students as they progress through the project and also creates a unique narrative about the learning behaviors of the teams. Not only does this allow the teaching team to identify students' learning strategies, it can be the basis for data-driven teaching improvements. While our digital solution addresses the call of EDM researchers for the development of more systems that are able to identify students' learning behaviors [28, 29], it also draws the attention of researchers in the area to further investigate the potential of using EDM concepts to improve collaborative reflection in design thinking projects in the context of university-industry collaboration.

\section{Conclusion}

This paper presents InnoPulse, a digital solution supporting team members and coaches in performing collaborative reflection in creativity-driven engineering projects. The system was developed based on previous studies on reflective practices, data mining methods and interviews $(\mathrm{N}=22)$ with design thinking experts and students. InnoPulse was tested in a real-world context with master's students using design thinking for engineering projects to solve complex business challenges proposed by industry partners.

Our study contributes to the literature by connecting design thinking to teamwork analytics research. We discuss how educational data mining techniques can be used to support students in developing sophisticated collaborative reflection activities in creativity-driven engineering projects. Additionally, this study contributes to practice by proposing a digital solution for systematic collaborative reflection and its design requirements which can inform developers and designers to propose further improvements.

Our study is not without limitations. First, it would be worthwhile to test InnoPulse for a longer period of time. Due to the limited testing time, students conducted reflection sessions on every test day, which limited their perception of when reflections would be necessary. By allowing more time, students would be able to decide when is the ideal time to conduct the reflection sessions. Second, considering that 7 out of 10 interviewed coaches were coaching on a professional educational program, the specific needs of the teaching team of students merit further elaboration. A fruitful area for further work would be to use InnoPulse to identify the different learning profiles of students, similarly to what was done in a recent study [36]. A more in-depth understanding of the different learning profiles of students learning design thinking can inform the creation of applications for predictive behavior, which is in line with calls from EDM researchers [26, 27].

\section{Acknowledgment}

Authors would like to thank the support from the Hasso Plattner Design Thinking Research Program (HPDTRP) and the SUGAR Network (https://sugar-network.org/).

\section{References}

[1] S. L. Beckman and M. Barry, "Innovation as a learning process: Embedding design thinking," California management review, vol. 50, no. 1, pp. 25-56, 2007.

[2] M. Wiesche, L. Leifer, F. Uebernickel, M. Lang, E. Byler, N. Feldmann, J. P. Garcia-Cifuentes, K. Höltää-Otto, K. Kelly, G. Satzger, et al., "Teaching innovation in interdisciplinary environments: Toward a design thinking syllabus," In Proceedings of the SIGED International Conference on Information Systems Education and Research., 2018.

[3] J. Jussila, J. Raitanen, A. Partanen, V. Tuomela, V. Siipola, and I. Kunnari, "Rapid product development in university-industry collaboration: Case study of a smart design project," Technology Innovation Management Review, vol. 10, no. 3, 2020.

[4] V. Nagaraj, N. Berente, K. Lyytinen, and J. Gaskin, "Team design thinking, product innovativeness, and the moderating role of problem unfamiliarity," Journal of Product Innovation Management, vol. 37, no. 4, pp. 297-323, 2020.

[5] L. Przybilla, K. Klinker, M. Lang, M. Schreieck, M. Wiesche, and H. Krcmar, "Design thinking 
in digital innovation projects-exploring the effects of intangibility," IEEE Transactions on Engineering Management, 2020.

[6] K. Roth, D. Globocnik, C. Rau, and A.-K. Neyer, "Living up to the expectations: The effect of design thinking on project success," Creativity and Innovation Management, vol. 29, no. 4, pp. 667-684, 2020.

[7] S. Chen, R. Benedicktus, Y. Kim, and E. Shih, "Teaching design thinking in marketing: Linking product design and marketing strategy in a product development class," Journal of Marketing Education, vol. 40, no. 3, pp. 176-187, 2018.

[8] C. L. Dym, A. M. Agogino, O. Eris, D. D. Frey, and L. J. Leifer, "Engineering design thinking, teaching, and learning," Journal of engineering education, vol. 94, no. 1, pp. 103-120, 2005.

[9] D. A. Schön, "Designing as reflective conversation with the materials of a design situation," Knowledge-based systems, vol. 5, no. 1, pp. 3-14, 1992.

[10] T. Schoormann, J. Hofer, and R. Knackstedt, "Software tools for supporting reflection in design thinking projects," in Proceedings of the 53rd Hawaii International Conference on System Sciences, 2020.

[11] J. Hey, A. V. Pelt, A. Agogino, and S. Beckman, "Self-reflection: Lessons learned in a new product development class," Journal of Mechanical Design, 2007.

[12] D. de Paula, F. Dobrigkeit, and K. Cormican, "Doing it right-critical success factors for design thinking implementation," in Proceedings of the Design Society: International Conference on Engineering Design, vol. 1, pp. 3851-3860, Cambridge University Press, 2019.

[13] H. Plattner, "An introduction to design thinking," Institute of Design at Stanford, pp. 1-15, 2013.

[14] F. Uebernickel, L. Jiang, W. Brenner, B. Pukall, T. Naef, and B. Schindlholzer, Design Thinking: The Handbook. World Scientific, 2020.

[15] M. Prilla, "Supporting collaborative reflection at work: A socio-technical analysis," AIS Transactions on Human-Computer Interaction, vol. 7, no. 1, pp. 1-17, 2015.

[16] S. Doorley, S. Witthoft, et al., Make space: How to set the stage for creative collaboration. John Wiley \& Sons, 2012.

[17] T. Herrmann, A. Carell, and J. Nierhoff, "Creativity barometer: an approach for continuing micro surveys to explore the dynamics of organization's creativity climates," in Proceedings of the 8th ACM conference on Creativity and cognition, pp. 345-346, 2011.

[18] M. Fire, G. Katz, Y. Elovici, B. Shapira, and L. Rokach, "Predicting student exam's scores by analyzing social network data," in Active Media Technology, pp. 584-595, 2012.

[19] K. J. Keen and L. Etzkorn, "Predicting Students' Grades in Computer Science Courses Based on Complexity Measures of Teacher's Lecture Notes," Journal of Computing Sciences in Colleges, vol. 24, pp. 44-48, 2009.

[20] International Educational Data Mining Society, "educationaldatamining.org," 2018.

[21] A. Dutt, M. A. Ismail, and T. Herawan, "A Systematic Review on Educational Data Mining," IEEE Access, vol. 5, no. c, pp. 15991-16005, 2017.
[22] J. Gamulin, O. Gamulin, and D. Kermek, "Data mining in hybrid learning: Possibility to predict the final exam result," in 2013 36th International Convention on Information and Communication Technology, Electronics and Microelectronics (MIPRO), pp. 591-596, 2013.

[23] C. Romero and S. Ventura, "Educational Data Mining: A Review of the State of the Art," IEEE Transactions on Systems, Man, and Cybernetics, Part C (Applications and Reviews), vol. 40, pp. 601-618, nov 2010.

[24] R. Teusner, K.-A. Rollmann, and J. Renz, "Taking Informed Action on Student Activity in MOOCs," in Proceedings of the Fourth (2017) ACM Conference on Learning@Scale-L@S'17,pp.149-152, 2017.

[25] D. Buenaño-Fernandez, W. Villegas-CH, and S. Luján-Mora, "The use of tools of data mining to decision making in engineering education-a systematic mapping study," Computer Applications in Engineering Education, vol. 27, no. 3, pp. 744-758, 2019.

[26] A. Behr, M. Giese, H. D. Teguim Kamdjou, and K. Theune, "Dropping out of university: a literature review," Review of Education, vol. 8, no. 2, pp. 614-652, 2020 .

[27] C. Bradberry and J. Pittges, "A design theoretic approach for smarter advising using educational data mining," 2020.

[28] G. Allen, R. Davies, N. Ball, C. Albrecht, and N. Bakir, "Using educational data mining to identify and analyze student learning strategies," 2019.

[29] L. Shi, A. I. Cristea, M. S. K. Awan, M. Hendrix, and C. Stewart, "Towards understanding learning behavior patterns in social adaptive personalized e-learning systems.," Association for Information Systems, 2013.

[30] K. Peffers, T. Tuunanen, M. A. Rothenberger, and S. Chatterjee, "A design science research methodology for information systems research," Journal of management information systems, vol. 24, no. 3, pp. 45-77, 2007.

[31] A. Knöpfel, B. Gröne, and P. Tabeling, Fundamental Modeling Concepts: Effective Communication of IT Systems. J. Wiley \& Sons.

[32] F. D. Davis, "Perceived usefulness, perceived ease of use, and user acceptance of information technology," MIS Quarterly, vol. 13, p. 319, Sept. 1989.

[33] B. Scott-Hill, C. Anslow, J. Ferreira, M. Kropp, M. Mateescu, and A. Meier, "Visualizing progress tracking for software teams on large collaborative touch displays," in 2020 IEEE Symposium on Visual Languages and Human-Centric Computing (VL/HCC), pp. 1-5, 2020.

[34] I. Rauth, E. Köppen, B. Jobst, C. Meinel, et al., "Design thinking: An educational model towards creative confidence," in DS 66-2: Proceedings of the 1st international conference on design creativity (ICDC 2010), 2010

[35] I. Hawryszkiewycz, S. Pradhan, and R. Agarwal, "Design thinking as a framework for fostering creativity in management and information systems teaching programs," in Pacific Asia Conference on Information Systems, PACIS 2015-Proceedings, 2015.

[36] T. Haskamp, A. Paul, E. Stöckli, D. de Paula, and F. Uebernickel, "Implementing design thinking for non-designers: Learning profiles from a q-methodology study," in International Society for Professional Innovation Management (ISPIM), 2020. 